\title{
Remote sensing approach for spatial planning of land management interventions in West African savannas
}

\section{Heiskanen, Janne}

2017

Heiskanen , J , Liu , J , Valbuena , R , Aynekulu , E , Packalen , P \& Pellikka , P 2017 , ' Remote sensing approach for spatial planning of land management interventions in West

African savannas ' , Journal of Arid Environments , vol. 140 , pp. 29-41 . https://doi.org/10.1016/j.jaridenv.2016.12.00

http://hdl.handle.net/10138/307224

https://doi.org/10.1016/j.jaridenv.2016.12.006

cc_by

acceptedVersion

Downloaded from Helda, University of Helsinki institutional repository.

This is an electronic reprint of the original article.

This reprint may differ from the original in pagination and typographic detail.

Please cite the original version. 
Preprint of the manuscript published in Journal of Arid Environments.

Final version: http://dx.doi.org/10.1016/j.jaridenv.2016.12.006.

\section{Remote sensing approach for spatial planning of land management interventions in West African savannas}

Janne Heiskanen ${ }^{a}{ }^{*}$, Jinxiu Liua, Ruben Valbuena ${ }^{b}$, Ermias Aynekuluc, Petteri Packalen ${ }^{b}$, Petri Pellikka a

a Department of Geosciences and Geography, University of Helsinki, Finland

b School of Forest Sciences, University of Eastern Finland, Joensuu, Finland

c World Agroforestry Centre (ICRAF), Nairobi, Kenya

${ }^{*}$ Corresponding author. E-mail address: janne.heiskanen@helsinki.fi 


\begin{abstract}
Forest management, agroforestry and tree planting are some of the key approaches to sustainable rural development, and climate change adaptation and mitigation in West African savannas. However, the planning of land management interventions is hindered by the lack of information at relevant spatial resolution. We examined predictive models for mapping various tree, soil and species diversity attributes with a comparison of RapidEye and Landsat imagery. The field data was collected in the vicinity of the community-managed forest in southern Burkina Faso, where the main environmental threats are agricultural expansion and fuelwood extraction. The modelling was done using Random Forest algorithm. According to our results, tree crown cover and correlated attributes, such as basal area and tree species richness, were predicted most accurately. High spatial resolution RapidEye imagery provided the best accuracy but difference to medium resolution Landsat imagery was negligible for most attributes. Burn scar masked Landsat time series performed similar to dry season single date Landsat imagery, but the former avoids image selection and mosaicking, and could be less sensitive to artifacts due to the burn scars. The presented approach provides valuable information on important tree, soil and species diversity attributes for spatial planning of land management interventions.
\end{abstract}

Keywords: Canopy cover; Carbon stocks; Biodiversity; RapidEye; Landsat, Burkina Faso 


\section{Introduction}

Land degradation due to agricultural expansion driven by the growing population, unsustainable use of wood fuel and climate variability are the main environmental threats in the savannas of West Africa. Forest management, agroforestry and tree planting are among the key land management approaches to sustainable rural development, restoration of land productivity and biodiversity, and climate change adaptation (Bayala et al., 2014; Sinare and Gordon, 2014). Furthermore, the tree-based interventions contribute to global climate change mitigation objectives and, for example, the carbon sequestration potential of the agroforestry parklands is widely recognized (e.g., Takimoto et al., 2008).

The planning of land management interventions is, however, hindered by the lack of suitable spatial information. Data on forest and woodland resources is also necessary for engagement in international initiatives such as Reducing Emissions from Deforestation and Forest Degradation (REDD+). Although continental scale spatial databases are available for some of the key attributes, such as biomass (Avitabile et al., 2016) and soil attributes (Hengl et al., 2015), those data have low spatial resolution and miss information, for example, on plant alpha (local) diversity (Revermann et al., 2016). Some authors have also found existing data unreliable in the savannas (Herrmann et al., 2013; Brandt et al., 2016). Furthermore, although vegetation and soil attributes can be inventoried in the field concurrently, databases including both types of information are scarce. Therefore, more localized information, and integrated assessments of trees, soils and biodiversity at landscape scale, are required.

Land cover maps based on remote sensing (RS) have been commonly used in ecosystem service assessments, but RS data can be used also for predicting various attributes as continuous variables (Andrew et al., 2014). Field measurements, for example, from National Forest Inventories, and RS are typically used in combination for generating such information in more developed countries (e.g., Reese et al., 2003). Fixed area plots employed in forest inventories and carbon projects, and include basic tree measurements, such as, diameters and species, can be used for computing a variety of attributes to characterize forest structure and tree species diversity. In principle, predictive models can be built for any vegetation or soil attribute but accuracy vary considerably between the attributes and RS data source. 
In the semi-arid Sudano-Sahelian zone, RS has been used primarily to analyze changes in vegetation productivity and broad vegetation types over large areas, and relatively little attention has been given to mapping tree attributes (Karlson and Ostwald, 2015). However, mapping tree crown cover (or canopy cover) and biomass, have received growing attention in the African savannas (e.g., Karlson et al., 2015; Halperin et al., 2016). Tree crown cover is an important attribute in forest definitions, which makes it particularly important for REDD+ (Romijn et al., 2013), but it has also multiple other applications (Halperin et al., 2016). Attention on biomass raise from the needs to quantify, map and monitor carbon pools (Avitabile et al., 2016). In the semi-arid areas, it is also related to biodiversity, environmental processes, such as hydrological cycle, soil erosion and land degradation, and ecosystem variability and resilience (Eisenfelder et al., 2012). Furthermore, RS can contribute to the assessment of biodiversity in multiple ways (e.g., Lausch et al., 2016) but alpha diversity has been commonly studied by using diversity indices, such as species richness and Shannon index (Rocchini et al., 2016). However, such approaches to mapping tree species diversity have rarely been tested in Africa (Maeda et al., 2014; Revermann et al., 2016).

Spatial information on soil attributes related to agricultural productivity and land degradation risks is crucial for planning land management interventions (Vågen et al., 2013b). Hence, predictive soil mapping has got increasing interest in Africa as soil data has been gathered across the continent (Hengl et al., 2015; Vågen et al., 2016). For example, soil organic carbon (SOC) and nitrogen contents relate to several important soil attributes, and are sensitive to land use and land degradation (Vågen and Winowiecki, 2013). Topsoil SOC content is essential for soil productivity, which makes its maintenance an important management goal in the SudanoSahelian zone (Bationo and Buerkert, 2001). Furthermore, in the West African parklands, a large fraction of total carbon stock typically resides in the soil (Takimoto et al., 2008), which emphasize its role in carbon inventories.

Reasonable spatial resolution, good availability, repeatability, cost and well-established processing methods are reasons why medium resolution satellite imagery are likely to remain as an important RS data source (Karlson et al., 2015; Halperin et al., 2016) although more advanced, yet expensive technologies, such as Light Detection and Ranging (LiDAR) and imaging spectroscopy, are superior for some tasks (e.g., Fassnacht et al., 2014). Landsat imagery were made freely available in 2008, most recent Landsat 8 Operational Land Imager (OLI) 
provides valuable data continuity, and availability of medium resolution imagery is increasing by Sentinel-2 satellites (Wulder et al., 2015). However, also several commercial satellite sensors provide high spatial resolution imagery with reasonable cost for many purposes. Halperin et al. (2016) compared OLI and RapidEye sensors for tree crown cover prediction in miombo woodlands of Zambia, but in general, comparisons of RS data sources are few in African savannas.

The dry forests and savanna woodlands pose both opportunities and challenges for optical RS (Eisfelder et al., 2012; Karlson et al., 2015). The tree cover is relatively sparse in the woodlands and hence reflectance signal should not saturate, which is typical for denser vegetation. In open woodlands, image texture could be also an important predictor of tree related attributes (Djaroudib, 1993), and hence high spatial resolution could be a considerable advantage. Furthermore, strong seasonality in rainfall drives a phenological cycle that can serve as an additional information source (Karlson et al., 2015; Brandt et al., 2016). The field layer dominates canopy reflectance throughout the seasonal cycle but the trees have the greatest contribution on reflectance during the dry season when the field layer is mostly senescent (Fuller et al., 1997). This makes dry season imagery particularly relevant but exploiting the full seasonal variation has become more feasible with freely available data (Liu et al., 2016). The challenges of optical RS, on the other hand, include large contribution of soil and bedrock on reflectance (Eisfelder et al., 2012; Karlson et al., 2015), lack of observations during rainy season (Brandt et al., 2016), frequent fires (Gessner et al., 2015), and large number of tree species (Karlson et al., 2015).

In this study, our objective was to examine predictive models for mapping various tree, soil and species diversity attributes for spatial planning of land management interventions in West African savannas. In more detail, we examined how accuracy of the predictions varies between attributes, and between high resolution RapidEye and medium resolution Landsat imagery. For Landsat, we considered single date imagery from the dry and rainy season, but also examined a time series of all available Landsat imagery for one year. 


\section{Material and methods}

\subsection{Study area}

The study area was located in the southern Burkina Faso in the Ziro province $\left(11^{\circ} 44^{\prime} \mathrm{N} 1^{\circ} 56^{\prime} \mathrm{W}\right)$ (Fig. 1a). This area belongs to the Sudanian regional center of endemism (White, 1983) and West Sudanian savanna ecoregion (Olson et al., 2001). The mean annual precipitation is 827 $\mathrm{mm}$ and the mean annual temperature is $27.5^{\circ} \mathrm{C}$ with most precipitation falling between May and September (Hijmans et al., 2005). In the Köppen-Geiger climate classification, the study area lies in the transition of Arid steppe (BSh) and tropical savannah climate types (Aw) (Peel et al., 2007). Topographically, the area is relatively flat with a mean elevation of $350 \mathrm{~m}$ above sea level. The most common soil type is plinthosols with subsurface accumulation of ironoxides, kaolinitic clay and quartz (plinthite) (Jones et al., 2013).

(b)

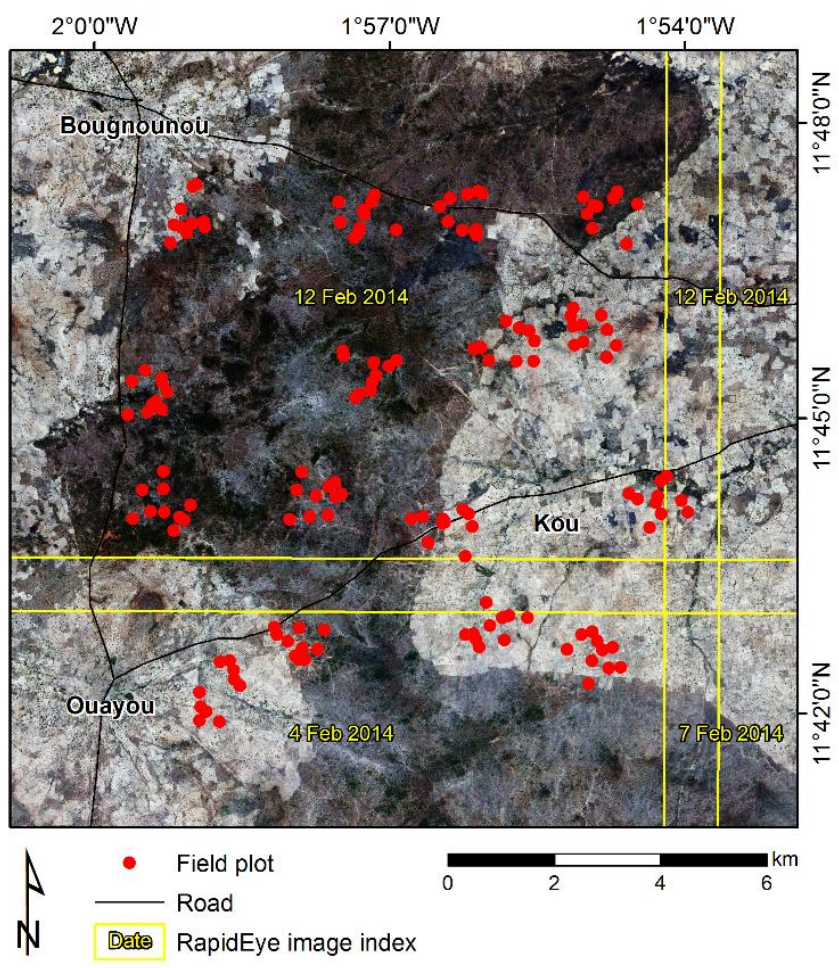

Fig. 1. (a) Location of the study area and (b) field plots on top of RapidEye image mosaic (true color composite). Also the extents of four RapidEye imagery with overlaps and acquisition dates are shown. 
Land cover is characterized by woodlands, agroforestry parklands, cropland and settlements (Liu et al., 2016). The area is an important source of fuelwood and charcoal to the major towns, and majority of the remaining forests is under community forest management and protection (Chantiers d'Aménagement Forestier, CAF) (Arevalo, 2016). The agriculture in the area is a mixture of traditional subsistence farming of, for example, sorghum, millet and maize, and cultivation of cash crops, such as cotton, sesame and peanuts. Woodlands are partly used for grazing. Furthermore, bushfires due to anthropogenic and natural causes are common in the dry season (Gessner et al., 2015).

The most common tree species in the woodlands are Anogeissus leiocarpa and Vitellaria paradoxa. Other common species are Burkea africana, Combretum molle, Lannea acida, Detarium microcarpum, Combretum fragrans, Acacia dudgeoni and Balanites aegyptiaca (Valbuena et al., 2016). The ground layer is dominated by perennial grasses. Scattered Vitellaria paradoxa (Shea nut tree) are the most common tree species in the crop fields.

\subsection{Field data}

We collected field data from an area of $10 \mathrm{~km} \times 10 \mathrm{~km}$ between December 2013 and February 2014 (Fig. 1b). The sampling design was based on the Land Degradation Surveillance Framework (LDSF) (Vågen et al., 2013a). The 10,000 ha site was stratified into 16 tiles, which were sampled by 100 ha clusters. Each cluster had ten circular 0.1 ha field plots (radius 17.84 $\mathrm{m}$ ), and each plot four circular 0.01 ha subplots (radius $5.64 \mathrm{~m}$ ). Cluster and field plot center points were randomly placed. The field plots were positioned by a consumer grade GPS receiver (Trimble Juno 3B) with an accuracy of 1.3-2.8 m.

Stems having diameter at breast height $(D B H, \mathrm{~cm})>4$ were inventoried. All larger stems $(D B H>$ 10) were measured for $D B H$ in the 0.1 ha plot. Species was determined for each tree by a local forester. Tree height $(H, \mathrm{~m})$ and crown diameter $(C D, \mathrm{~m})$ were measured for a sample of stems (smallest, median and largest $D B H)$. Furthermore, smaller stems $(D B H \leq 10)$ were counted in the 0.01 ha subplots, and $H$ and $C D$ were measured for median $D B H$ stem. As detailed in Valbuena et al. (2016), non-linear mixed effect modelling was used for predicting height $(\widehat{H})$ and linear regression for predicting $C D\left(\widehat{C D}=2.204+0.179 \times D B H, \mathrm{R}^{2}=0.57, \mathrm{RMSE}=1.7\right.$ $\mathrm{m}$ ) for stems that were not measured. Standing dead trees were inventoried similar to the living 
stems. Furthermore, downed dead wood was sampled in the 0.01 ha subplots (diameter $>4$ $\mathrm{cm})$, recording the length of the pieces lying inside the plot, diameter at mid-length and decay class.

For estimating aboveground biomass $(A G B)$, we used the pan-tropical allometric model of Chave et al. (2014) based on $D B H, \widehat{H}$ and wood specific gravity $(\rho)$. The online databases (Zanne et al., 2009; World Agroforestry Centre, 2015) and literature (Nygård and Elfving, 2000) were searched for $\rho$ at the closest taxonomic level. Species-specific $\rho$ was found for $97.5 \%$ of the stems, and genus-specific $\rho$ for the rest. Mean $\rho$ was used if there were multiple values for a species. In addition to $A G B$, we also used a generic volume function and form factor of 0.42 for estimating stem volume (Magnussen and Reed, 2004).

The belowground biomass $(B G B)$ was estimated using aboveground biomass and root:shoot ratio of 0.275 (Mokany et al., 2006). Biomass of standing dead trees was computed similarly to living trees but using the mean $\rho$ as species could not be determined. The pieces of the downed dead wood were assumed cylinder-shaped, and volume computed based on diameter and length. The volume was converted to biomass using the mean $\rho$ and decay class reduction factors of 1.00, 0.78 and 0.45 for 'sound', 'intermediate' and 'rotten', respectively (Waddell, 2002). Finally, we converted all biomasses ( $A G B, B G B$, dead wood) to carbon using carbon fraction of 0.47 (IPCC, 2006).

In addition to trees, we collected topsoil samples from 0-20 cm depth at the four subplots using a $7.6 \mathrm{~cm}$ diameter soil auger. In each plot, the soil samples were mixed thoroughly to form one composite sample. Then, the air-dried soil samples were grounded and sieved through $2 \mathrm{~mm}$ sieve prior to analysis (Aynekulu et al., 2011). Finally, SOC and nitrogen concentrations (g kg1) were analyzed using thermal oxidation method (Skjemstad and Baldock, 2008).

Based on the tree inventory and soil sampling, we computed an extensive set of plot-level attributes (Table 1). Hereafter, these attributes are called Y-variables. Stem density (Dens, stems ha-1), basal area $\left(B A, \mathrm{~m}^{2} \mathrm{ha}^{-1}\right)$, mean diameter $(\overline{D B H}, \mathrm{~cm})$ and mean height $(\bar{H}, \mathrm{~m})$ were computed based on the field measured and predicted values. Tree crown cover $(C C, \%)$ was estimated from the canopy area index $\left(C_{W}\right)$ (Torello-Raventos et al., 2013). First, the crown area was computed for each stem based on $\widehat{C D}$, and $C_{W}$ was taken as a ratio of total crown area 
and plot area. When a tree had multiple stems, only the stem with the maximum $C D$ was considered. Then, $C C$ was computed as: $C C=1-\exp \left(-C_{W}\right)$. Stem volume $\left(V, \mathrm{~m}^{3} \mathrm{ha}^{-1}\right)$ and aboveground carbon stock ( $\left.A G C, \mathrm{Mg} \mathrm{ha}^{-1}\right)$ were based on tree-wise predictions. We preferred SOC $(S O C, \%)$ and nitrogen $(N, \%)$ contents for mapping, but also computed SOC stock (Mg ha${ }^{1}$ ) based on the bulk density of the sample $\left(\mathrm{g} \mathrm{m}^{-3}\right)$ and fraction of the coarse fragments (> $\left.2 \mathrm{~mm}\right)$ (Aynekulu et al., 2011). The total carbon stock $\left(C, \mathrm{Mg} \mathrm{ha}^{-1}\right)$ was taken as a sum of aboveground and belowground biomass, dead wood and SOC carbon stocks.

Finally, we described the tree species diversity by tree species richness, and Shannon and Simpson diversity indices (e.g., Krebs, 1999). Species richness $(S)$ was simply the number of tree species in the plot. Shannon index $\left(H^{\prime}\right)$ was computed as: $H^{\prime}=-\sum_{i=1}^{S} p_{i} \ln \left(p_{i}\right)$ and Simpson index $(D)$ as: $D=1-\sum_{i=1}^{S} p_{i}^{2}$, where $p_{i}$ was the relative abundance (share in the total number of trees) of each species $i=1,2, \ldots, S$. Both $H^{\prime}$ and $D$ were set zero when there were no trees present in the plots. Furthermore, A. leiocarpa and V. paradoxa were the most tree common tree species (Valbuena et al., 2016). Therefore, we also included basal areas of $A$. leiocarpa (A.lei, $\left.\mathrm{m}^{2} \mathrm{ha}^{-1}\right)$ and V. paradoxa $\left(V\right.$.par, $\left.\mathrm{m}^{2} \mathrm{ha}^{-1}\right)$ in Y-variables.

Table 1. Descriptive statistics for the Y-variables $(n=160)$. Total carbon stock $(C)$ includes aboveground, belowground, dead wood and soil organic carbon. 59 plots were cultivated (i.e. annual crops were present) and 101 plots were not cultivated.

\begin{tabular}{|c|c|c|c|c|}
\hline Y-variable & Description & Range & Mean & SD \\
\hline Dens & Stem density, stems ha ${ }^{-1}$ & $0-1935$ & 470 & 406 \\
\hline$B A$ & Basal area at breast height, $\mathrm{m}^{2} \mathrm{ha}^{-1}$ & $0-16.1$ & 5.3 & 3.8 \\
\hline$\overline{D B H}$ & Quadratic mean diameter at breast height, $\mathrm{cm}$ & $0-48.1$ & 20.5 & 8.7 \\
\hline $\bar{H}$ & Basal area weighted mean height, $\mathrm{m}$ & 0-13.1 & 7.2 & 2.3 \\
\hline$C C$ & Tree crown cover, \% & 0-70.4 & 26.9 & 18.1 \\
\hline$V$ & Stem volume, $\mathrm{m}^{3} \mathrm{ha}^{-1}$ & $0-62.0$ & 17.0 & 12.8 \\
\hline$A G C$ & Aboveground carbon stock, $\mathrm{Mg} \mathrm{ha}^{-1}$ & $0-31.7$ & 8.8 & 6.8 \\
\hline SOC & Soil organic carbon content, \% & $0.29-2.49$ & 0.81 & 0.36 \\
\hline$N$ & Soil nitrogen content, \% & $0.015-0.107$ & 0.043 & 0.017 \\
\hline C & Total carbon stock, Mg ha-1 & $5.9-75.9$ & 27.3 & 14.4 \\
\hline$S$ & Tree species richness, species & $0-14.0$ & 5.6 & 3.8 \\
\hline$H^{\prime}$ & Shannon index & $0-2.5$ & 0.9 & 0.6 \\
\hline$D$ & Simpson index & $0-1.0$ & 0.5 & 0.3 \\
\hline A. lei & Basal area of $A$. leiocarpus, $\mathrm{m}^{2} \mathrm{ha}^{-1}$ & 0-10.9 & 1.2 & 2.2 \\
\hline V.par & Basal area of $V$. paradoxa, $\mathrm{m}^{2} \mathrm{ha}^{-1}$ & $0-4.5$ & 1.1 & 1.1 \\
\hline
\end{tabular}


Table 2. Summary of the remote sensing data.

\begin{tabular}{|c|c|c|}
\hline Input data & Description & Dates \\
\hline RapidEye & $\begin{array}{l}\text { Mosaic of four RapidEye imagery. } \\
\text { Ortho product (Level } 3 A \text { ). }\end{array}$ & $\begin{array}{l}4 \text { Feb 2014, } 7 \text { Feb 2014, } \\
12 \text { Feb } 2014\end{array}$ \\
\hline $\begin{array}{l}\text { Landsat (closest to } \\
\text { RapidEye) }\end{array}$ & $\begin{array}{l}\text { Landsat } 8 \mathrm{OLI} \text { image. } \\
\text { Surface reflectance product. }\end{array}$ & 16 Feb 2014 \\
\hline Dry season Landsat & $\begin{array}{l}\text { Landsat } 8 \mathrm{OLI} \text { image. } \\
\text { Surface reflectance product. }\end{array}$ & 12 Nov 2013 \\
\hline Rainy season Landsat & $\begin{array}{l}\text { Landsat } 8 \mathrm{OLI} \text { image. } \\
\text { Surface reflectance product. }\end{array}$ & 8 Jun 2014 \\
\hline Landsat time series & $\begin{array}{l}14 \text { Landsat } 7 \mathrm{ETM}+\text { and } 21 \text { Landsat } 8 \mathrm{OLI} \text { imagery. } \\
\text { Surface reflectance product. }\end{array}$ & 1 Nov $2013-31$ Oct 2014 \\
\hline
\end{tabular}

\subsection{RapidEye data}

RapidEye is a constellation of five satellites that can provide high spatial resolution imagery with temporal resolution up to daily recurrence. Each satellite has a multi-spectral push broom imager with five spectral bands corresponding to blue $(0.440-0.510 \mu \mathrm{m})$, green $(0.520-0.590$ $\mu \mathrm{m})$, red (0.630-0.685 $\mu \mathrm{m})$, red edge (0.690-0.730 $\mu \mathrm{m})$ and near infrared (NIR, 0.760-0.850 $\mu \mathrm{m}$ ) parts of the spectrum. Ground sampling distance in nadir is $6.5 \mathrm{~m}$ and radiometric resolution is 12 bits.

We purchased imagery best corresponding to the time of field inventory from RapidEye $\operatorname{archive}^{1}$ (Table 2). The Ortho product (Level 3A) with radiometric, geometric and terrain corrections and $5 \mathrm{~m} \times 5 \mathrm{~m}$ pixel size was used. The study area was covered by four $25 \mathrm{~km} \times 25$ km tiles based on imagery acquired 4, 7 and 16 February 2014 (Fig. 1b).

The digital numbers were converted to radiance $\left(\mathrm{W} \mathrm{m}^{-2} \mathrm{sr}^{-1} \mu \mathrm{m}\right)$ using the scale factor provided in the metadata and atmospherically corrected to surface reflectance $\left(R_{b}\right.$, where $b$ denotes spectral band) using the Fast Line-of-Sight Atmospheric Analysis of Spectral Hypercubes (FLAASH) algorithm implemented in ENVI 5.0 software (Exelis Visual Information Solutions, Inc.). As one of the tiles showed clear difference in reflectance, probably due to difference in view azimuth, we performed relative calibration of the spectral bands by linear regression based on overlapping area between the tiles. The image from 12 February was used as a

\footnotetext{
1 http://eyefind.rapideye.com/
} 
reference image as it had the largest cover with the field plots (Fig. 1b). In the final mosaic, boundaries between imagery were not visible. We assessed the geometry of the mosaic against other geospatial data from the area (e.g., GPS tracks of roads) and did not consider further geometric correction necessary.

\subsection{Landsat imagery and time series parameters}

We downloaded all available Landsat Enhanced Thematic Mapper Plus (ETM+) and Landsat 8 Operational Land Imager (OLI) Surface Reflectance Climate Data Record (CDR) imagery from USGS EarthExplorer ${ }^{2}$ for the time period between November 2013 and October 2014 (path 195, row 52). The CDR imagery are atmospherically corrected using Landsat Ecosystem Disturbance Adaptive Processing System (LEDAPS) tool (Masek et al., 2006), and clouds and shadows are masked using Fmask method (Zhu and Woodcock, 2012). The data included surface reflectance $\left(R_{b}\right)$ in blue (ETM+ 0.45-0.52 $\mu \mathrm{m}$, OLI 0.45-0.51 $\left.\mu \mathrm{m}\right)$, green (ETM+ 0.52-0.60 $\mu \mathrm{m}$, OLI 0.53$0.59 \mu \mathrm{m})$, red (ETM+ 0.63-0.69 $\mu \mathrm{m}$, OLI 0.64-0.67 $\mu \mathrm{m})$, NIR (ETM+ 0.77-0.90 $\mu \mathrm{m}$, OLI 0.85$0.88 \mu \mathrm{m})$ and two shortwave infrared bands, SWIR1 (ETM+1.55-1.75 $\mu \mathrm{m}$, OLI 1.57-1.65 $\mu \mathrm{m}$ ) and SWIR2 (ETM+2.09-2.35 $\mu \mathrm{m}$, OLI 2.11-2.29 $\mu \mathrm{m})$. The full time series consisted of a total of 35 imagery (14 ETM+ and 21 OLI imagery) (Liu et al., 2016).

In order to compare RapidEye and Landsat imagery, we selected three cloud-free imagery for a detailed analysis (Table 2). OLI image from 12 February 2014 was selected because the acquisition date was closest to that of RapidEye imagery. Moreover, the OLI imagery from 12 November 2013 and 8 June 2014 were selected as the best quality dry and rainy season imagery, respectively.

In addition to the single date imagery, we used a harmonic model (Eq. 1) to capture the seasonality in $R_{b}$ and normalized difference vegetation index (NDVI, Table 3):

$$
\hat{y}_{t}=a+b \times \sin \left(\frac{2 \pi t}{T}+c\right)+e_{t}
$$

\footnotetext{
2 http://earthexplorer.usgs.gov/
} 
where $\hat{y}_{t}$ is the predicted value ( $R_{b}$ or NDVI) on Julian date $t, T$ is frequency (365 days), $a, b$, and $c$ are the model parameters (intercept, amplitude and phase), and $e_{t}$ is the residual error. Parameter $a$ is an estimate of the annual mean, $b$ captures the inter-annual changes caused by vegetation phenology, and $c$ represents the timing of the phenological events. Since the model (Eq. 1) can be simplified as a linear model, we used the ordinary least squares method to fit it for each pixel (Liu et al., 2016).

Large parts of the study area were burnt during dry season (November to March), and observations corresponding to the burn scars departed from the harmonic model, influencing the model fit and parameters. Therefore, those observations were removed (Liu et al., 2016). First, the model (Eq. 1) was fit using burn area index (BAI, Chuvieco et al., 2002) as a response variable $(y)$. Then the observations were removed as outliers based on a threshold. The threshold was computed as a difference of predicted BAI plus 2.5 times root mean square error (RMSE) and observed BAI. If the threshold was less than zero, the pixel was detected as a burn scar, otherwise the pixel was regarded unburnt. Since the burn scars could not be identified and masked once, we employed the method iteratively as long as further observations were not removed.

\subsection{Remote sensing predictors}

The RS predictors (hereafter X-variables) included typical spectral and textural features used with RapidEye and Landsat imagery, and seasonal features based on Landsat time series (see Supplement 1 for full list).

For RapidEye, X-variables included reflectance in the spectral bands, vegetation indices (VI) and image texture derived from the grey-level co-occurrence matrices (GLCM). VIs requiring a red edge band could be used only with RapidEye, whereas those based on SWIR were used only for Landsat (Table 3). Mean value across all spectral bands was also computed as it is used sometimes in biodiversity studies (Maeda et al., 2014). We computed GLCM measures including mean, variance, homogeneity, contrast, dissimilarity, entropy, second moment, and correlation (Haralick et al., 1973) based on the first principal component image and 'glcm' package (Zvoleff, 2015) in R (R Core Team, 2015). We set the offset distance as one pixel and measures were averaged over four directions at 64 quantization level. We also used three window sizes $(3 \times 3$, 
$5 \times 5$ and $7 \times 7$ pixels). Finally, all the RapidEye data were aggregated by a factor of six to $30 \mathrm{~m}$ $\times 30 \mathrm{~m}$ resolution to approximately match the field plot size. For spectral bands and VIs, we computed both their means and standard deviations. For textural features, we computed only their means (Supplement 1).

For the single-date Landsat imagery, X-variables included reflectance in the spectral bands, VIs and mean reflectance. We computed standard deviation for $3 \times 3$ pixels window as field plots corresponded approximately with the field plot size. Due to the lower spatial resolution of Landsat, we did not include image texture besides standard deviations.

For Landsat time series, X-variables included estimates of model parameters (Eq. 1) for the spectral bands and normalized difference vegetation index (NDVI). Furthermore, we computed other VIs (Table 3), mean reflectance across the spectral bands and standard deviation for $3 \times$ 3 pixels window using parameter $a$ estimates.

Finally, we extracted all the RapidEye and Landsat X-variables at $30 \mathrm{~m} \times 30 \mathrm{~m}$ resolution for modelling using the field plot center coordinates and bilinear resampling method (i.e. as a mean of four nearest pixels). 
Table 3 . Summary of vegetation indices. $R_{\text {blue }}, R_{\text {green }}, R_{\text {red }}, R_{N I R}, R_{\text {red edge }}$ and $R_{S W I R 1}$ corresponds to surface reflectance in blue, green, red, near infrared, red edge and shortwave infrared spectral bands of RapidEye and Landsat sensors, respectively.

\begin{tabular}{|c|c|c|}
\hline Index & Formula & Reference \\
\hline Simple ratio (SR) & $R_{N I R} / R_{\text {red }}$ & Tucker (1979) \\
\hline $\begin{array}{l}\text { Normalized difference } \\
\text { vegetation index (NDVI) }\end{array}$ & $\left(R_{N I R}-R_{\text {red }}\right) /\left(R_{N I R}+R_{\text {red }}\right)$ & Tucker (1979) \\
\hline Green NDVI (GNDVI) & $\left(R_{N I R}-R_{\text {green }}\right) /\left(R_{\text {NIR }}+R_{\text {green }}\right)$ & Gitelson et al. (1996) \\
\hline $\begin{array}{l}\text { Enhanced vegetation } \\
\text { index (EVI) }\end{array}$ & $2.5 \times \frac{\left(R_{\text {NIR }}-R_{\text {red }}\right)}{\left(R_{\text {NIR }}+6 \times R_{\text {red }}-7.5 \times R_{\text {blue }}+1\right)}$ & Huete et al. (2002) \\
\hline $\begin{array}{l}\text { Vogelmann red edge } \\
\text { index (VREI1) }\end{array}$ & $R_{\text {NIR }} / R_{\text {red edge }}$ & Vogelmann et al. (1993) \\
\hline Red edge NDVI (RENDVI) ${ }^{1}$ & $\left(R_{N I R}-R_{\text {red edge }}\right) /\left(R_{\text {NIR }}+R_{\text {red edge }}\right)$ & Gitelson \& Merzlyak (1994) \\
\hline Infrared SR (ISR) ${ }^{2}$ & $R_{N I R} / R_{S W I R 1}$ & Fernandes et al. (2003) \\
\hline $\begin{array}{l}\text { Normalized difference } \\
\text { water index (NDWI) }\end{array}$ & $\left(R_{N I R}-R_{S W I R 1}\right) /\left(R_{N I R}+R_{S W I R 1}\right)$ & Gao (1996) \\
\hline
\end{tabular}

${ }^{1}$ Only RapidEye; ${ }^{2}$ Only Landsat

\subsection{Random Forest regression}

We used Random Forest (RF) regression (Breiman, 2001) for modelling and carrying out predictions for the entire study area. RF is an ensemble modelling technique where a 'forest' consist of a large number of regression trees. A regression tree is a succession of regression models (the nodes separating branches) obtained by recursively partitioning the explained variance. In RF, each tree is built from a random sample (approximately two-thirds) of the training data drawn with replacement. At each node, a random subset of the X-variables is used to identify the most efficient split. The most efficient split is defined by identifying the predictor variable and the split point that results in the largest reduction in the residual sum of squares between the sample observations and the node mean. The final predictions are derived by averaging the predictions of the individual trees (Breiman, 2001). RF has been shown to learn effectively non-linear and complex patterns, making no assumptions about data distribution, requiring very few parameters to be set, and producing predictions only within the range of the modelling data. These are all important benefits when several forest attributes have to be modelled. 
We used 'RandomForest' package (Liaw and Wiener, 2002) in R (R Core Team, 2015). The number of trees was set to 500 and the number of predictors tested at each node was the square root of the total number of predictors (Breiman, 2001). Because of the large number of Xvariables, we used a RF based variable selection algorithm (Genuer et al., 2010) in 'VSURF' package (Genuer et al., 2015) to remove redundant X-variables. In the final 'prediction step' of the algorithm, only a minimum set of X-variables remains for prediction. We also fitted models using all the X-variables in order to evaluate the effect of variable selection on accuracy.

First, we run VSURF five times for each Y-variable and RS data set as some minor variation occurred between the selected X-variables. Then, out of the five VSURF runs, we selected the subset that produced the smallest RMSE. The final results were computed as an average of 20 RF runs because results varied slightly between single RF runs. In all the RF runs, we computed accuracy statistics by using leave-one-out cross validation (LOOCV) (Packalén et al., 2012). In other words, single RF run included 160 runs where one observation in turn was left out and the remaining observations were used as the training set. The prediction was made to the observation left out. In addition to RMSE, the accuracy statistics included bias (mean residual error) and pseudo coefficient of determination $\left(R^{2}\right)$ based on correlation between the observed and predicted values of LOOCV.

Finally, we generated the maps for selected tree, soil and species diversity attributes. Similarly to previous step, the predictions at $30 \mathrm{~m} \times 30 \mathrm{~m}$ resolution were computed as an average of 20 RF model runs.

\section{Results}

The modeling results varied considerably among the Y-variables (Fig. 2). Because of the large number of models, detailed results including full accuracy statistics and selected X-variables are given in Supplement 2. The relative RMSE ranged mostly between 25 and $50 \%$ but was at best only $112.2 \%$ for A. lei and $93.1 \%$ for $V$.ppar (Fig. 2a). Although some models attained small RMSE $(\bar{H}, N$ and $S O C)$, the predictions were poorly correlated with the observed values (Fig. $2 \mathrm{~b}$ ). $B A, C C$ and $S$ provided the best trade-off between the RMSE and $\mathrm{R}^{2}$. The Y-variables with 
particularly poor $\mathrm{R}^{2}$ included $D B H, \bar{H}, D$ and $V$.par. The prediction bias was very small in every case (Supplement 2).

(a)

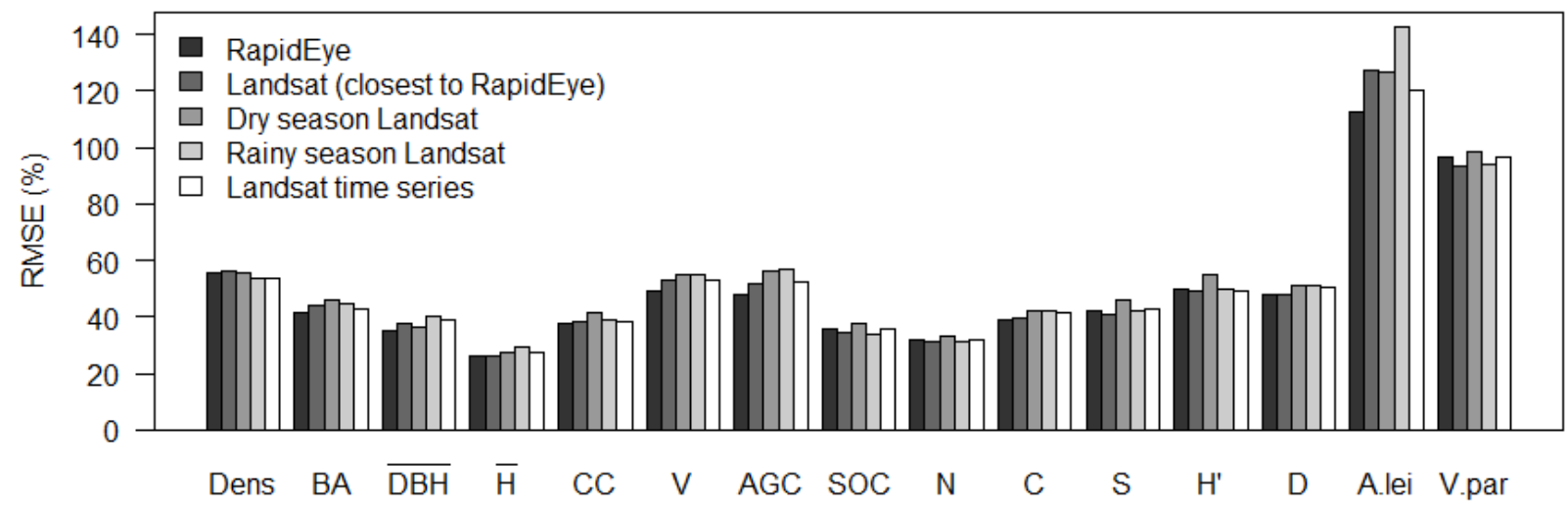

(b)

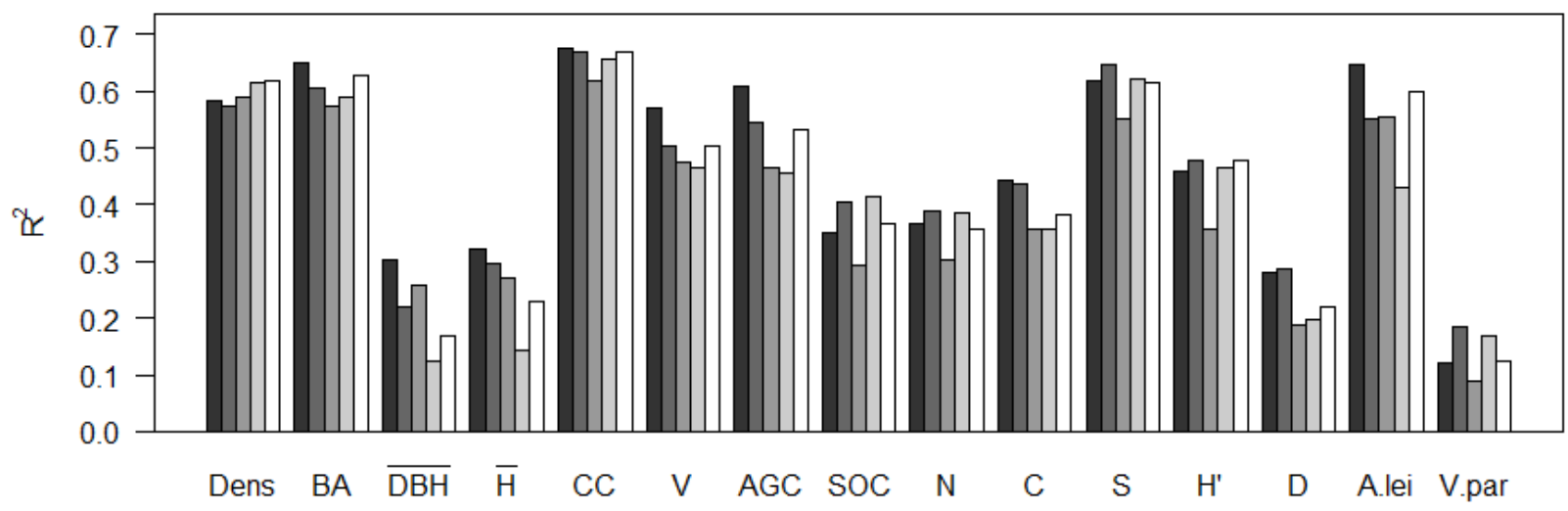

Fig. 2. (a) Relative root mean square error (RMSE \%) and (b) coefficient of determination ( $\mathrm{R}^{2}$ ) for all Y-variables (Table 1) and remote sensing data sets (Table 2). The results are based on leave-one-out cross-validation after variable selection for X-variables.

In order to better understand how model performance depends on Y-variable, we studied how Y-variables were correlated (Supplement 3). Strong correlations were apparent between some of the Y-variables (e.g., $C C$ and $B A$ ) as expected (both were based on Dens and $D B H$ ). However, some of the strong correlations were not as obvious, such as that between $C C$ and $S$. Furthermore, if Y-variables are strongly correlated, they are also likely to perform similarly in the regression modelling. This is demonstrated in Fig. 3, which shows that correlation of Yvariable with $C C$ (variable predicted most accurately by all RS data sets) is related to modelling results in terms of $\mathrm{R}^{2}$. 

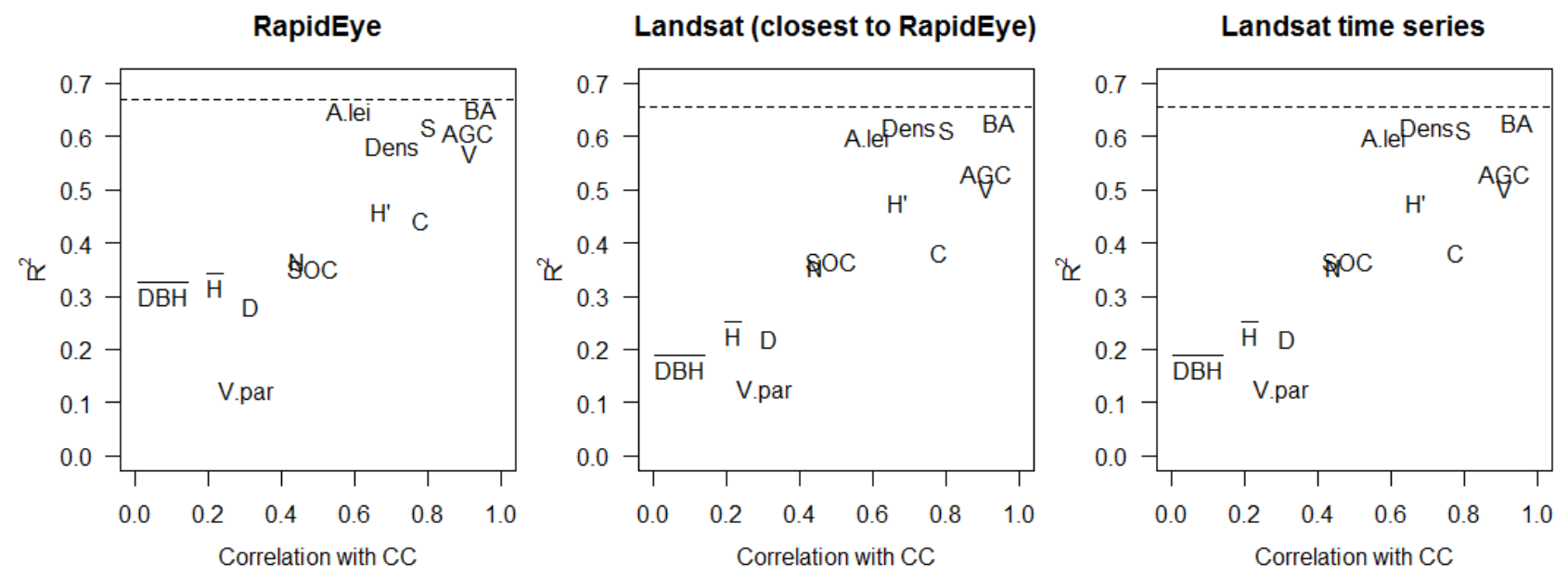

Fig. 3. Correlation (Pearson correlation coefficient) between tree crown cover $(C C)$ and Yvariables (Table 1) versus coefficient of determination $\left(\mathrm{R}^{2}\right)$ for Random Forest models based on RapidEye image, Landsat image closest to RapidEye and Landsat time series. $\mathrm{R}^{2}$ for $C C$ models are shown with dashed line.

In comparison to differences between the Y-variables, the variation between RS data sets was relatively small (Fig. 2, Supplement 2). However, among the data sets, RapidEye was usually ranked the best according to RMSE (ranked first on majority). Furthermore, Landsat image closest in time to RapidEye ranked second and Landsat time series as third. The dry season and rainy season Landsat imagery provided the poorest accuracies. Scatterplots of observed and predicted values for selected Y-variables and the three best RS data sets demonstrate the small differences in the model performance (Fig. 4). Some under-prediction of large values is typically present, in particular when the number of observations in upper tail is low (e.g., $A G C$ and $S O C$ ). Furthermore, it is clear that some of the Y-variables, such as $\overline{D B H}$ and $\bar{H}$, are predicted poorly (Supplement 4). Although accuracy statistics are not presented, the scatterplots show that results can be considerably improved if predictions are averaged to cluster-level (Fig. 4, Supplement 4). 

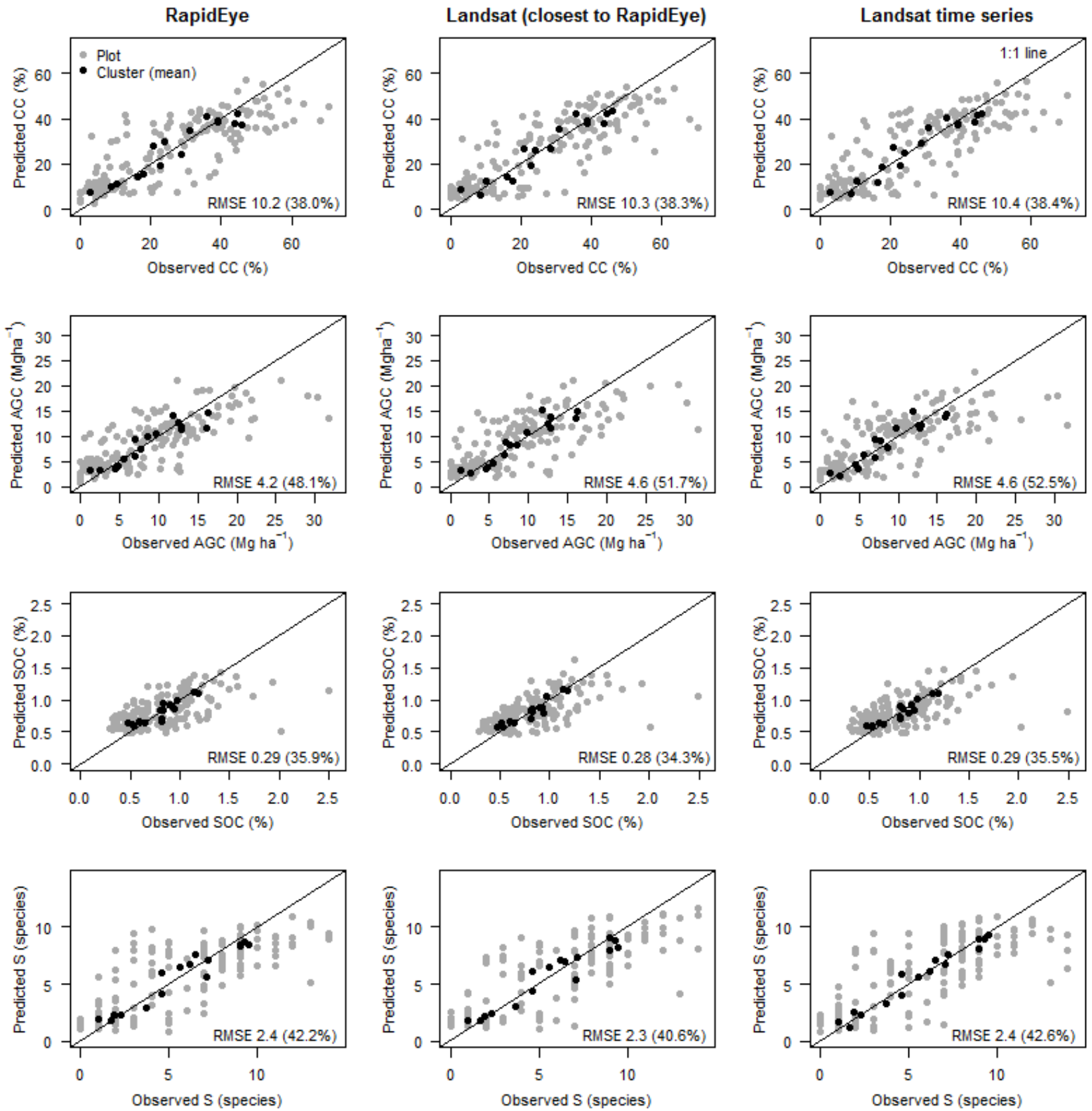

Fig. 4. Observed versus predicted values of tree crown cover ( $C C$ ), aboveground carbon ( $A G C)$, soil organic carbon content $(S O C)$ and tree species richness $(S)$ based on RapidEye image, Landsat image (closest to RapidEye) and Landsat time series. RMSE given in the panels is based on field plots (i.e. not cluster-level mean values).

Variable selection improved all the models as shown by reduction in RMSE and improvement in $\mathrm{R}^{2}$ (Fig. 5). The number of $\mathrm{X}$-variables after the variable selection ranged 2-14, with most models having 5-9 X-variables (Supplement 2). In the case of dry season Landsat image and SOC, VSURF was unable to reduce number of $\mathrm{X}$-variables. 
For RapidEye, the most commonly selected and important X-variables were reflectance in blue and green spectral bands (Supplement 2). Also Vogelmann red edge index (VREI1), reflectance in red spectral band, enhanced vegetation index (EVI) and red edge NDVI (RENDVI) were often included. In addition to those, all the RapidEye models included standard deviation or GLCM textural features. Standard deviation for red spectral band and GLCM entropy ( $3 \times 3$ pixels) were selected most often but otherwise there was large variation in the selected X-variables.

(a)

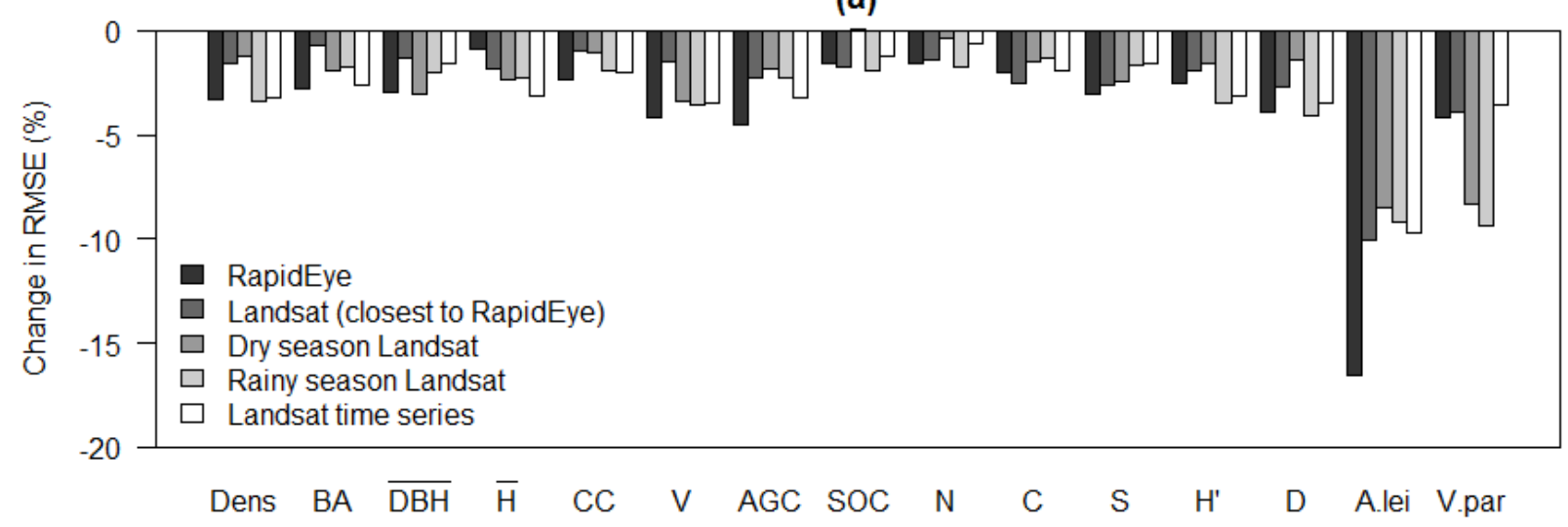

(b)

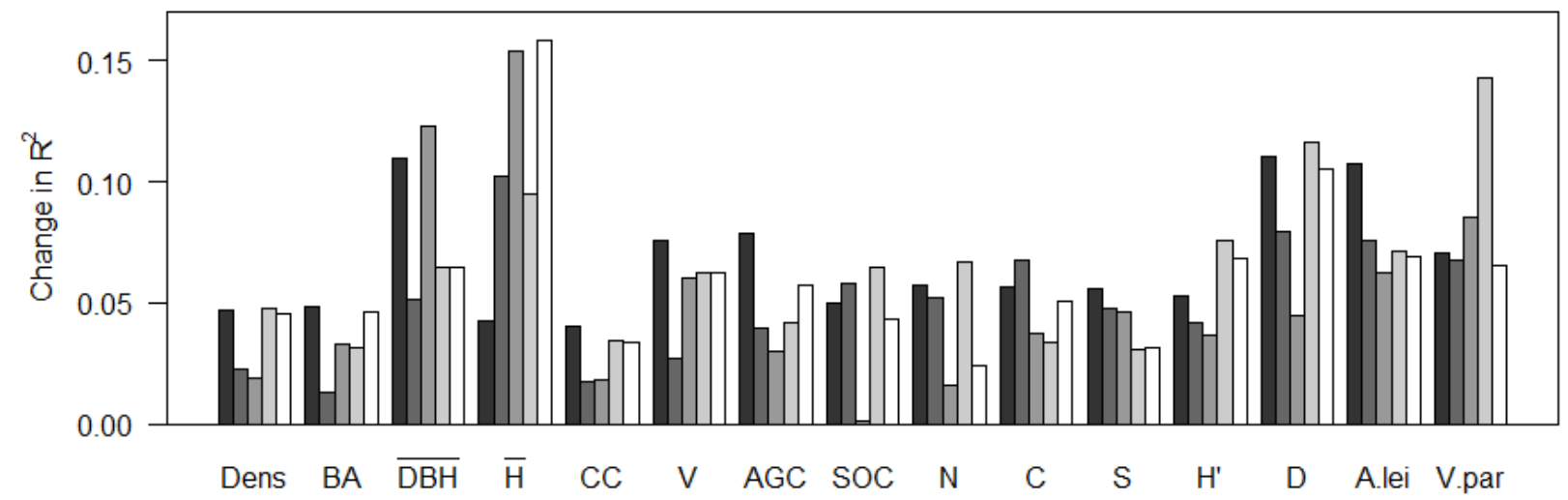

Fig. 5. Effect of variable selection on (a) relative root mean square error (RMSE \%) and (b) pseudo coefficient of determination $\left(R^{2}\right)$. Negative change in RMSE and positive change in $R^{2}$ refer to improvement in model performance after variable selection.

The blue and green spectral bands, and green NDVI (GNDVI) were the most common Xvariables for the Landsat image closest in time to RapidEye (Supplement 2). Also SWIR2 spectral band and mean of all spectral bands were commonly selected. Standard deviation of the infrared simple ratio (ISR) was the most often selected texture-related X-variable, but some 
models did not include standard deviation. GNDVI was also important for the dry and rainy season Landsat imagery along with blue, green and red spectral bands, EVI and normalized difference water index (NDWI). In the case of rainy season image, simple ratio (SR) was common but also most important variable in several models.

For Landsat time series, GNDVI and SR based on parameter $a$ (intercept) were selected most frequently, and usually ranked among the three most important X-variables (Supplement 2). Also parameter $a$ for blue, green and SWIR2 spectral bands, parameter $c$ (phase) for SWIR1 band, and mean of parameter $a$ for all spectral bands were commonly selected. Similar to other Landsat models, standard deviations did not occur among the most important X-variables.

The maps of $C C, A G C, S O C$ and $S$ based on RapidEye, Landsat image closest in time to RapidEye and Landsat time series are shown in Fig. 6. As expected by the small differences in the accuracy statistics, the spatial patterns of predictions agreed rather well. The boundaries between forest/woodlands and parklands/croplands are clearly visible in the maps of tree attributes. However, both parts of the landscape show considerable spatial variation. 


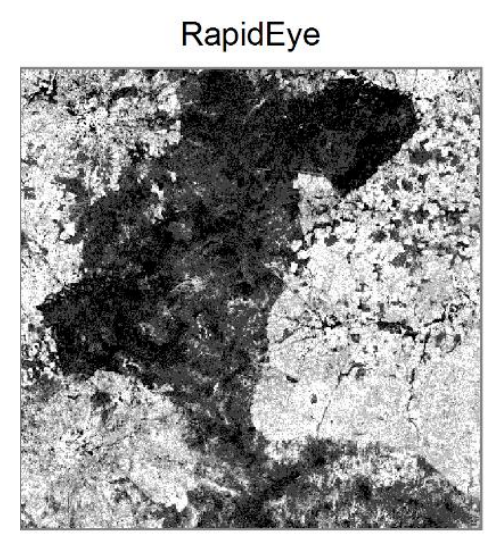

Landsat (closest to RapidEye)
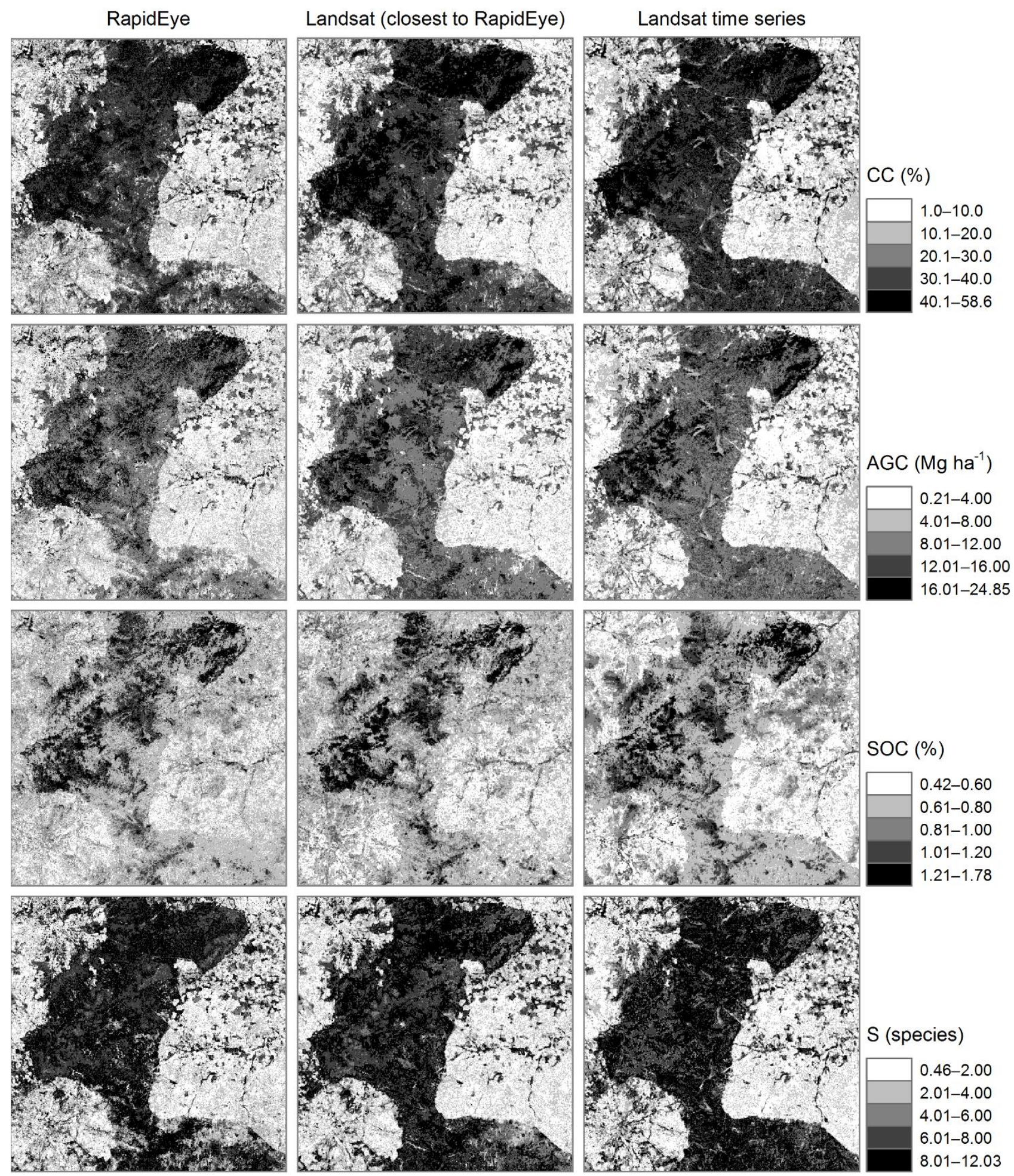

$S$ (species)

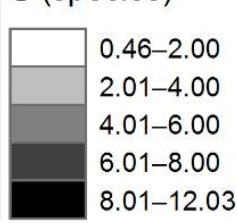

$\begin{array}{llll} & & & \\ & k & 6 & 9\end{array}$

Fig. 6. Maps of tree crown cover $(C C)$, aboveground carbon stock $(A G C)$, soil organic carbon content $(S O C)$ and tree species richness $(S)$ based on RapidEye image, Landsat image (closest to RapidEye) and Landsat time series. 
The most striking difference between the maps occurred in the southernmost woodlands of the study area where Landsat based predictions were in general higher than those based on RapidEye (Fig. 6). The differences larger than 15\% of CC occurred in that area (Fig. 7). This part was covered by the RapidEye image acquired 4 February 2013 (Fig. 1), and hence, the time difference between the RapidEye and Landsat image closest in time was almost two weeks. According to the visual analysis of Landsat time series, the southernmost woodlands burnt on late December 2012 or early January 2013. In the RapidEye image acquired sooner after burning, only the largest tree crowns that have not lost their green leaves were visible. Also according to the very high resolution imagery Bing maps ${ }^{3}$, those woodlands have greater $C C$ than predicted by RapidEye. Furthermore, when comparing RapidEye and Landsat time series (Fig. 7b), some large positive differences ( $>15 \%$ of $C C$ ) were also visible in the areas of very dark soil (RapidEye larger).

(a)

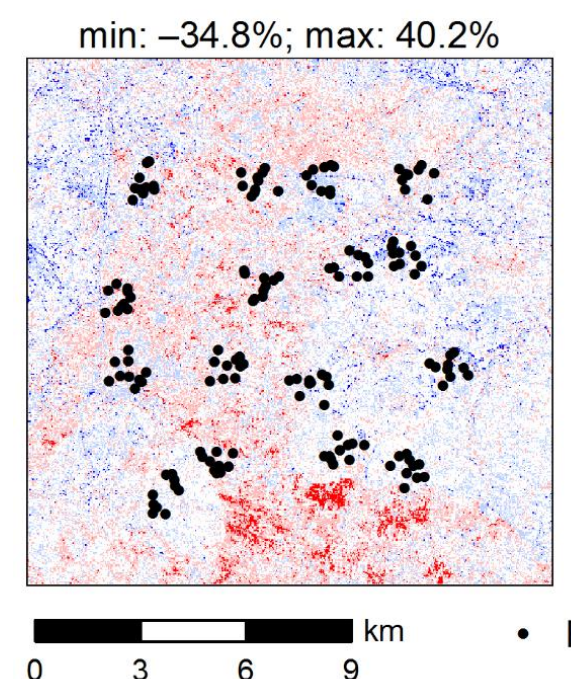

(b)

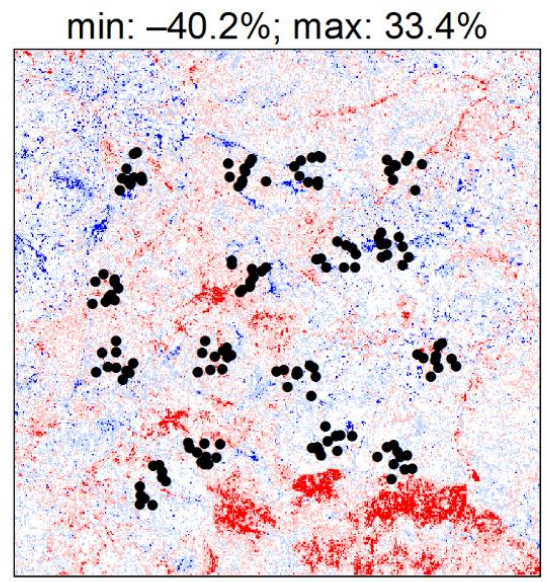

Difference in CC (\%)

Field plot (c)

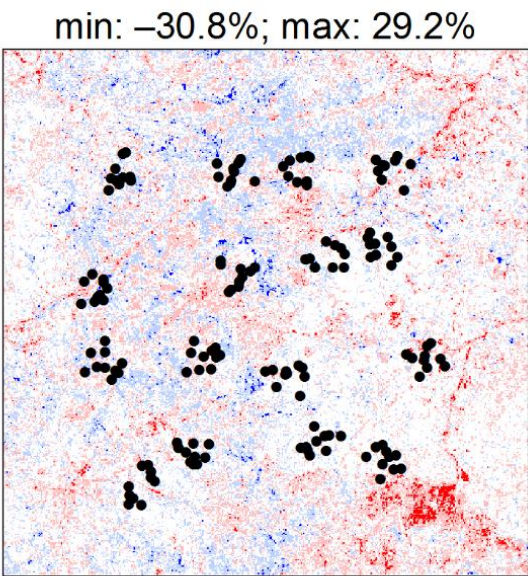

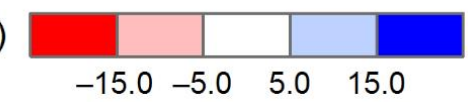

Fig. 7. Differences in predicted tree crown cover $(C C)$ values: (a) RapidEye minus Landsat (closest to RapidEye), (b) RapidEye minus Landsat time series and (c) Landsat (closest to RapidEye) minus Landsat time series. 


\section{Discussion}

In this paper, we developed predictive models for a range of tree, soil and biodiversity attributes based on high and medium resolution RS data from RapidEye and Landsat sensors. According to the results, the model performance varied considerably between the attributes (Y-variables) but relatively little between the RS data sets. The most accurate predictions were based on the late dry season RapidEye and Landsat imagery but Landsat time series might provide most robust predictions against the burn scars. Furthermore, our results showed that attributes correlated with $C C$ were predicted most successfully in the studied semi-arid environment.

The attribute predicted most accurately was $C C$. Including a local crown radius model based on crown radii measured in every plot, improved accuracy in comparison to $B A$, which was the most accurate field measurement (diameter was measured for every tree in the plot). It is known that $C C$ (or canopy closure) is among the most important attributes affecting the spectral response of forests and woodlands (Franklin and Strahler, 1988). Furthermore, reflectance is typically weakly dependent on height-related attributes as increase in tree height does not necessarily increase cover (Lefsky and Cohen, 2003). Therefore, it could be expected that $\bar{H}$, but also $V$ and $A G C$ which depend on height, are predicted less accurately than $C C$. Furthermore, the species specific maps are commonly asked by the end-users of the data, but like shown by our results, the prediction errors can be very large.

RS studies have usually concentrated on single vegetation attributes, such as $C C$ (e.g. Halperin et al., 2016) or compared only a few attributes, such as CC and $A G B$ (Karlson et al., 2015). Halperin et al. (2016) reviewed CC assessments for tropical dry forests of Africa and found that RMSE ranged between 7 and 13\% (e.g., Hansen et al., 2002; Wu et al., 2013; Karlson et al., 2015), which is similar to our results (RMSE 10.2-11.1\%). Karlson et al. (2015) modelled $A G B$ close to our study area and attained $\mathrm{R}^{2}$ of 0.57 and relative RMSE of $66.0 \%$, which are slightly worse than our best results for $A G C\left(\mathrm{R}^{2} 0.61\right.$, RMSE 48.1\%). Some authors have predicted $A G B$ based on remotely sensed $C C$ (Franklin and Hiernaux, 1991; Wu et al., 2013), and strong relationship was also evident in our data. Karlson et al. (2015) compared $C C$ and $A G B$, and reported smaller RMSE for $C C$ than $A G B$ (40.6\% versus $66.0 \%$ ). This is in line with our results and highlight the closer link between $C C$ and reflectance than between $A G B$ and reflectance. 
Only weak to moderate correlations were observed between tree and soil attributes, which could explain relatively poor accuracy of $S O C$ and $N$ predictions at the landscape scale. Vagen and Winowiecki (2013) and Vågen et al. (2013b) developed models for SOC and several other soil attributes using Landsat spectral bands. The $\mathrm{R}^{2}$ values for SOC were 0.65 and 0.86 (RMSE not given), respectively, but models were calibrated across several sites and greater range of SOC and environmental conditions, which could explain difference to our results (best $\mathrm{R}^{2} 0.41$ ). For the same reason, the landscape scale analysis is difficult to compare with continental scale studies that have used a large number of sampling sites across Africa (Hengl et al., 2015; Vågen et al., 2016).

We observed strong correlation between $C C$ and $S$, and hence also $S$ was predicted rather accurately. The spatial predictions of species diversity are scarce for dry forests and woodlands of Africa (Revermann et al., 2016). Some studies on biodiversity mapping have suggested that other descriptors of alpha diversity, such as $H^{\prime}$, which is less affected by rare species than $S$, would be more readily predicted by RS data (Oldeland et al., 2010). However, here $S$ was predicted more accurately than $H^{\prime}$ or $D$, particularly at low index values typical for agroforestry parklands and croplands dominated by single species and having treeless areas.

Both RapidEye and Landsat OLI fulfil spatial resolution requirements for planning land management interventions at landscape scale (e.g., Vågen and Winowieski, 2013). However, the benefits of higher spatial resolution of RapidEye imagery in prediction accuracy seem small in comparison to Landsat data, which is in line with conclusions of Halperin et al. (2016). In tropical woodlands, field plots smaller than 0.1 ha are rarely useful because of low stem density. When reference data have spatial resolution commensurate with Landsat data, the higher spatial resolution of RS data does not necessarily improve accuracy (Halperin et al., 2016).

Reflectance in the blue and green bands and GNDVI were important predictors (Y-variables) in the majority of the models. In Karlson et al. (2015), the panchromatic band was the most important spectral predictor of $C C$ and $A G B$. EVI and green and red bands were the most important predictors in the study of Halperin et al. (2016). This suggests that shorter wavelength are valuable for mapping in savannas. The red edge VIs (RENDVI, VREI1) were commonly selected to RapidEye models, which is contradictory to Halperin et al. (2016). Landsat SWIR band or NDWI was included in most Landsat models. Furthermore, SWIR2 
ranked as the most important predictor for $S O C$ in all but rainy season Landsat model. This is in accordance with Hengl et al. (2015) who found that MODIS SWIR reflectance was among the best predictors of SOC. Although some patterns are evident, there is still need for better understanding on the link between various land attributes and spectral responses in the savannas. However, the lack of SWIR band in RapidEye is a clear disadvantage in comparison to Landsat.

Texture has been considered useful in the savannas and other sparsely wooded areas with heterogeneous tree cover (e.g., Djaroudib, 1993). Here, several textural features were present in most RapidEye models. For Landsat, standard deviations occurred only rarely among the most important variables but usually one or two variables were selected. Textural features were also included in the best CC models of Karlson et al. (2015) and Halperin et al. (2016), and $A G B$ models of Karlson et al. (2015). However, in our models, textural features were not clearly more important for any of the attributes, for example, for tree species diversity indices which is often assumed (Oldeland et al., 2010; Maeda et al., 2014).

The dry season imagery have been found particularly useful for mapping vegetation attributes in the savannas (Karlson et al., 2015; Liu et al., 2016). The acquisition dates of RapidEye image and Landsat image closest to it correspond to late dry season (February). Those imagery performed in general better than the best image from early dry season (November) or the best image from early rainy season (June). Hence, the late dry season could provide better contrast between the trees and other vegetation (grasses, crops) because of phenological differences in the timing of leaf senescence (Karlson et al., 2015). However, bushfires are common in December and January, and recent burn scars can cause artifacts to predictions. In the early dry season, before the fires, predictions are not as accurate as phenological differences are not yet as pronounced (Brandt et al., 2016), although crops have been harvested in the late rainy season, which improves differentiation between natural vegetation and croplands. In the rainy season, trees, grasses and crops are green, and modelling results are poorer.

The potential of multi-temporal or seasonal data for mapping vegetation types and attributes in the savannas has been emphasized by previous studies (Karlson et al., 2015; Liu et al., 2016) although mostly using coarser spatial resolution imagery (Hermann et al., 2013; Revermann et al., 2016). Here, late dry season imagery performed slightly better than Landsat time series. 
However, the differences in accuracy were mostly small, and considering other benefits, time series could be preferred over single date imagery (Liu et al., 2016). A simple time series model makes use of all cloud-free observations for one year and subjective image selection is not required. Furthermore, mosaicking of several imagery or gap-filling due to clouds, cloud shadows, missing lines of ETM+ SLC-off imagery or burn scars is not required. In comparison to statistical metrics (e.g., Karlson et al., 2015), the method also provides estimates of annual minimum and maximum values (Liu et al., 2016).

Landsat imagery provide an excellent source of freely available data for mapping tree, soil and species diversity attributes measured in the field. The availability of free medium resolution imagery has been recently improved by Sentinel-2 data, and virtual constellations of Landsat and Sentinel-2 satellites will provide unprecedented temporal resolution at medium spatial resolution (Wulder et al., 2015). However, downloading and processing of annual Landsat imagery can be automated (Liu et al., 2016) but the Internet constraints remain in Africa and limit the downloading of RS data (Roy et al., 2010; Karlson and Ostwald, 2015). Therefore, easy access to seasonal metrics with minimum need for downloading, or access to a cloud computing platform is necessary for wider use of time series information in the study region.

The spatial predictions (Fig. 6) can be used for identifying areas of high and low attribute values at landscape scale, and locating target areas for land management interventions (e.g., Vågen and Winowiecki, 2013). In the simplest application, the sites meeting certain criteria could be mapped in GIS software based on one or several attributes. However, the criteria or threshold values are case-specific (i.e., depend on type of intervention), and even debated (Vågen et al., 2013b). Alternatively, maps can be utilized in participatory planning approaches. Furthermore, additional information, such as present land use, could be required. For example, Liu et al. (2016) attained high overall accuracy for cropland class (land cultivated or not) in the same study area. Finally, although mapping was the main purpose of this study, the predictions can be used, for example, to estimate forest area (Halperin et al., 2016).

Improvements in prediction accuracy are possible through better quality field data, additional predictors or alternative modelling methods. Accurate measurement of $C C$ is very time consuming (Korhonen et al., 2006). The method to estimate $C C$ in this study is practical and requires only few additional measurements to $D B H$ (Torello-Raventos et al., 2013). One way to 
improve the accuracy of $C C$ would include measuring $C D$ and position for each tree (Halperin et al., 2016). Alternatively, $C C$ could be interpreted from very high resolution imagery (Hansen et al., 2002; Karlson et al., 2015). Furthermore, the stem volume estimates were based on generic model (Magnussen and Reed, 2004) and biomass estimates on pan-tropical allometric models (Chave et al., 2014). Although these models give reasonable estimates across a wide range of conditions, local models should be used when available.

Some alternative predictors have been also used. Sometimes, tasseled cap transformation (brightness, greenness and wetness) has been applied for Landsat imagery (Karlson et al., 2015). Furthermore, ETM+ and OLI provide panchromatic band at $15 \mathrm{~m}$ spatial resolution and it can be used for computing additional textural features (Karlson et al., 2015). Halperin et al. (2016) found soil data useful for $C C$ modelling in addition to RS data. Revermann et al. (2016) used topographic predictors derived from digital elevation model to model species diversity. Furthermore, predictors related to fire frequency and timing of fire could be valuable (Halperin et al., 2016; Revermann et al., 2016). However, such data is available only at low spatial resolution and fire products at suitable resolution for landscape scale analysis are currently lacking.

RF has become popular method for predicting vegetation and soil attributes (Fassnacht et al., 2014; Hengl et al., 2015). Although RF has been often superior to other methods in terms of accuracy (Fassnacht et al., 2014), part of its popularity is due to simplicity of model fitting, which requires only very few parameters to be set (Belgiu and Drăguţ, 2016). This is a great advantage when several attributes needs to be predicted. However, when modelling small number of attributes, results should always be controlled against another method (Halperin et al., 2016). Sensitivity of RF to sampling design has been noted as one of its limitations (Belgiu and Drăguţ, 2016). When large values are rare, RF, like other regression tree methods, tends to underestimate them (Karlson et al., 2015; Halperin et al., 2016), which was observed also in our results. Stratified sampling design based on RS data should ensure appropriate data distribution for modelling. 


\section{Conclusions}

We demonstrated how fixed area plots, typically collected in forest and carbon inventories, can be coupled with RS data to generate spatial predictions of tree, soil and biodiversity attributes. The results highlight $C C$ as a multipurpose parameter that is best predicted by optical RS data, such as RapidEye and Landsat imagery. Therefore, it might be the case that attributes, such as $A G C$ and $S$, can be reliably predicted only as long as they are strongly correlated with $C C$. In the selected approach, the high spatial resolution RapidEye imagery provided only marginal improvement in comparison to the medium resolution Landsat data. The Landsat data offer good access to seasonal information through annual time series and includes SWIR bands, which explained variability in SOC content. Therefore, Landsat, and similar freely available medium resolution data, provide a good basis for mapping key attributes for planning land management interventions in the savannas of West Africa.

\section{Acknowledgements}

This work was supported by the Building Biocarbon and Rural Development in West Africa (BIODEV) project funded by the Ministry for Foreign Affairs of Finland. The authors are thankful for Dr. Jerome Tondoh (World Agroforestry Centre), François W. Kagambega and Idrissa Sawadogo (Institut de l'Environment et de Recherches Agricoles), and Dr. Markus Melin (University of Eastern Finland) for contributions in the field data collection.

\section{References}

Andrew, M.E., Wulder, M.A., Nelson, T.A., 2014. Potential contributions of remote sensing to ecosystem service assessments. Prog. Phys. Geog. 38, 328-353.

Arevalo, J., 2016. Improving woodfuel governance in Burkina Faso: The experts' assessment. Renew. Sust. Energ. Rev. 57, 1398-1408.

Aynekulu, E., Vagen, T-G., Shephard, K., Winowiecki, L., 2011. A protocol for modeling, measurement and monitoring soil carbon stocks in agricultural landscapes. Version 1.1. World Agroforestry Centre, Nairobi. 
Avitabile, V., Herold, M., Heuvelink, G., Lewis, S.L., Phillips, O.L., et al., 2016. An integrated pantropical biomass map using multiple reference datasets. Glob. Change Biol. 22, 1406-1420. Bationo, A., Buerkert, A., 2001. Soil organic carbon management for sustainable land use in Sudano-Sahelian West Africa. Nutr. Cycl. Agroecosys. 61, 131-142.

Bayala, J., Sanou, J., Teklehaimanot, Z., Kalinganire, A., Ouédraogo, S., 2014. Parklands for buffering climate risk and sustaining agricultural production in the Sahel of West Africa. Curr. Opin. Environ. Sustain. 6, 28-34.

Belgiu, M., Drăguţ L., 2016. Random forest in remote sensing: A review of applications and future directions. ISPRS J. Photogramm. 114, 24-31.

Brandt, M., Hiernaux, P., Tagesson, T., Verger, A., Rasmussen, K., et al., 2016. Woody plant cover estimation in drylands from Earth Observation based seasonal metrics. Remote Sens. Environ 172, 28-38.

Breiman, L., 2001. Random forests. Mach. Learn. 45, 5-32.

Chave, J., Réjou-Méchain, M., Búrquez, A., Chidumayo, E., Colgan, M.S., 2014. Improved allometric models to estimate the aboveground biomass of tropical trees. Glob. Change Biol. 20, 3177-3190.

Chuvieco, E., Martín, M.P., Palacios, A., 2002. Assessment of different spectral indices in the rednear-infrared spectral domain for burned land discrimination. Int. J. Remote Sens. 23, 5103-5110.

Djaroudib, K., 1993. Quantitative estimation of woody vegetation in the Sudano-Sahelian region. EARSeL Advances in Remote Sens. 2, 56-63.

Eisenfelder, C., Kuenzer, C., Dech, S., 2012. Derivation of biomass information for semi-arid areas using remote sensing data. Int. J. Remote Sens. 33, 2937-2984.

Fassnacht, F.E., Hartig, F., Latifi, H., Berger, C., Hernández, J., et al., 2014. Importance of sample size, data type and prediction method for remote sensing-based estimations of aboveground forest biomass. Remote Sens. Environ 154, 102-114.

Fernandes, R., Butson, C., Leblanc, S., Latifovic, R., 2003. Landsat-5 TM and Landsat-7 ETM+ based accuracy assessment of leaf area index products for Canada derived from SPOT-4 VEGETATION data. Can. J. Remote Sens. 29, 241-258.

Franklin, J., Hiernaux, P., 1991. Estimating foliage and woody biomass in Sahelian and Sudanian woodlands using a remote sensing model. Int. J. Remote Sens. 12, 1387-1404.

Franklin, J., Strahler, A.H., 1988. Invertible canopy reflectance modeling of vegetation structure in semiarid woodland. IEEE Trans. Geosci. Remote Sens. 26, 809-825 
Fuller, D.O., Prince, S.D., Astle, W.L., 1997. The influence of canopy strata on remotely sensed observations of savanna-woodlands. Int. J. Remote Sens. 18, 2985-3009.

Gao, B, 1996. NDWI-A normalized difference water index for remote sensing of vegetation liquid water from space. Remote Sens. Environ. 58, 257-266.

Genuer, R., Poggi, J.-M., Tuleau-Malot, C., 2010. Variable selection using Random Forests. Pattern Recogn. Lett. 31, 2225-2236.

Genuer, R., Poggi, J.-M., Tuleau-Malot, C., 2015. VSURF: Variable selection using random forests. R package version 1.0.2. http://CRAN.R-project.org/package=VSURF

Gessner, U., Knauer, K., Kuenzer, C., Dech, S., 2015. Land surface phenology in a West African savanna: impact of land use, land cover and fire, in: Kuenzer, C., Dech, S., Wagner, W. (Eds.), Remote Sensing Time Series. Springer International Publishing, Dordrecht, pp. 203-223.

Gitelson, A., Merzlyak, M.N., 1994. Spectral Reflectance Changes Associated with Autumn Senescence of Aesculus Hippocastanum L. and Acer Platanoides L. Leaves. Spectral Features and Relation to Chlorophyll Estimation. J. Plant Physiol. 143, 286-292.

Gitelson, A.A., Kaufman, Y.J., Merzlyak, M.N., 1996. Use of a green channel in remote sensing of global vegetation from EOS-MODIS. Remote Sens. Environ. 58, 289-298.

Halperin, J., LeMay, V., Coops, N., Verchot, L., Marshall, P., Lochhead, K., 2016. Canopy cover estimation in miombo woodlands of Zambia: Comparison of Landsat 8 OLI versus RapidEye imagery using parametric, nonparametric, and semiparametric methods. Remote Sens. Environ 179, 170-182.

Hansen, M.C., DeFries, R.S., Townshend, J.R.G., Marufu, L., Sohlberg, R., 2002. Development of a MODIS tree cover validation data set for Western Province, Zambia. Remote Sens. Environ. 83, 320-335.

Haralick, R.M., Shanmugam, K., Dinstein, I, 1973. Textural features for image classification. IEEE Trans. Syst. Man Cybern. 3, 610-621.

Hengl, T., Heuvelink, G.B.M., Kempen, B., Leenaars, J.G.B., Walsh, M.G., et al., 2015. Mapping soil properties of Africa at $250 \mathrm{~m}$ resolution: random forests significantly improve current predictions. PLoS ONE 10, e0125814.

Herrmann, S., Wickhorst, A., Marsh, S., 2013. Estimation of tree cover in an agricultural parkland of Senegal using rule-based regression tree modeling. Remote Sens. 5, 4900-4918.

Hijmans, R.J., Cameron, S.E., Parra, J.L., Jones, P.G., Jarvis, A., 2005. Very high resolution interpolated climate surfaces for global land areas. Int. J. Climatol. 25, 1965-1978. 
Huete, A., Didan, K., Miura, T., Rodriguez, E.P., Gao, X., et al., 2002. Overview of the radiometric and biophysical performance of the MODIS vegetation indices. Remote Sens. Environ. 83, 195-213.

IPCC, 2006. 2006 IPCC Guidelines for National Greenhouse Gas Inventories. Eggleston H.S., Buendia L., Miwa K., Ngara T., Tanabe, K. (Eds.). IGES, Japan.

Jones, A., Breuning-Madsen, H., Brossard, M., Dampha, A., Deckers, J., et al. (Eds.), 2013. Soil Atlas of Africa. European Commission, Luxemburg.

Karlson, M., Ostwald, M., 2016. Remote sensing of vegetation in the Sudano-Sahelian zone: A literature review from 1975 to 2014. J. Arid Environ. 124, 257-269.

Karlson, M., Ostwald, M., Reese, H., Sanou, J., Tankoano, B., Mattsson, E., 2015. Mapping tree canopy cover and aboveground biomass in Sudano-Sahelian woodlands using Landsat 8 and random forest. Remote Sens. 7, 10017-10041.

Korhonen, L., Korhonen, K.T., Rautiainen, M., Stenberg, P., 2006. Estimation of forest canopy cover: a comparison of field measurement techniques. Silva Fenn. 40, 577-588.

Krebs, C.J., 1999. Ecological Methodology, 2nd ed. Benjamin/Cummings, San Francisco.

Lausch, A., Bannehr, L., Beckmann, M., Boehm, C., Feilhauer, H., Hacker, J.M., Heurich, M., Jung, A., Klenke, R., Neumann, C., Pause, M., Rocchini, D., Schaepman, M.E., Schmidtlein, S., Schulz, K., Selsam, P., Settele, J., Skidmore, A.K., Cord, A.F. (2016). Linking Earth Observation and taxonomic, structural and functional biodiversity: Local to ecosystem perspectives. Ecol. Indic. 70, 317-339.

Lefsky, M.A., Cohen, W.B., 2003. Selection of remotely sensed data. In: Wulder, M.A., Franklin, S.E. (Eds.), Remote sensing of forest environments: concepts and case studies. Kluwer Academic, Boston, pp. 13-46.

Liaw, A., Wiener, M., 2002. Classification and Regression by randomForest. R News 2, 18-22.

Liu, J., Heiskanen, J., Aynekulu, E., Maeda, E.E., Pellikka, P.K., 2016. Land cover characterization in West Sudanian savannas using seasonal features from annual Landsat time series. Remote Sens. 8, 365.

Maeda, E.E., Heiskanen, J., Thijs, K.W., Pellikka, P.K.E., 2014. Season-dependence of remote sensing indicators of tree species diversity. Remote Sens. Lett. 5, 404-412.

Magnussen, S., Reed, D., 2004. Modelling for estimation and monitoring. Knowledge reference for national forest assessments. Food and Agriculture Organization of the United Nations. http://www.fao.org/forestry/8758/en/ (accessed 19.8.2016) 
Masek, J.G., Vermote, E.F., Saleous, N.E., Wolfe, R., Hall, F.G., et al., 2006. A Landsat surface reflectance dataset for North America, 1990-2000. IEEE Geosci. Remote Sens. Lett. 3, 6872.

Mokany, K., Raison, R.J, Prokushkin, A.S, 2006. Critical analysis of root:shoot ratios in terrestrial biomes. Global Change Biol. 12, 84-96.

Nygård, R., Elfving, B, 2000. Stem basic density and bark proportion of 45 woody species in young savanna coppice forests in Burkina Faso. Ann. For. Sci. 57, 143-153.

Oldeland, J., Wesuls, D., Rocchini, D., Schmidt, M., Jürgens, N., 2010. Does using species abundance data improve estimates of species diversity from remotely sensed spectral heterogeneity? Ecol. Indic. 10, 390-396.

Olson, D.M., Dinerstein, E., Wikramanayake, E.D., Burgess, N.D., Powell, G.V.N., et al., 2001. Terrestrial Ecoregions of the World: A New Map of Life on Earth. Bioscience 51, 933-938.

Packalén, P., Temesgen, H., Maltamo, M., 2012. Variable selection strategies for nearest neighbor imputation in remote sensing based forest inventory. Can. J. Remote Sens. 38, 113.

Peel, M.C., Finlayson, B.L., McMahon, T.A., 2007. Updated world map of the Köppen-Geiger climate classification. Hydrol. Earth Syst. Sc. 11, 1633-1644.

R Core Team, 2015. R: A language and environment for statistical computing. R Foundation for Statistical Computing, Vienna, Austria. https://www.R-project.org/.

Reese, H., Nilsson, M., Granqvist Pahlén, T., Hagner, O., Joyce, S., et al., 2003. Countrywide estimates of forest variables using satellite data and field data from the National Forest Inventory. Ambio 32, 542-548.

Revermann, R., Finckh, M., Stellmes, M., Strohbach, B.J., Frantz, D., Oldeland, J. (2016). Linking land surface phenology and vegetation-plot databases to model terrestrial plant -diversity of the Okavango basin. Remote Sens. 8, 370.

Rocchini, D., Boyd, D.S., Féret, J.-B., Foody, G.M., He, K.S., Lausch, A., Nagendra, H., Wegmann, M., Pettorelli, N. (2016). Satellite remote sensing to monitor species diversity: potential and pitfalls. Remote Sensing in Ecology and Conservation 2, 25-36.

Romijn, E., Ainembabazi, J.H., Wijaya, A., Herold, M., Angelsen, A., et al., 2013. Exploring different forest definitions and their impact on developing REDD+ reference emission levels: A case study for Indonesia. Environ. Sci. Policy 33, 246-259.

Roy, D. P., Ju, J., Mbow, C., Frost, P., Loveland, T., 2010. Accessing free Landsat data via the Internet: Africa's challenge. Remote Sens. Let. 1, 111-117. 
Sinare H., Gordon, L.J., 2015. Ecosystem services from woody vegetation on agricultural lands in Sudano-Sahelian West Africa. Agr. Ecosyst. Environ. 200, 186-199.

Skjemstad J., Baldock, J.A., 2008. Total and organic carbon. In: Carter, M.R., Gregorich, E.G. (Eds.), Soil sampling and methods of analysis. Soil Science Society of Canada, pp. 225-238.

Takimoto, A., Nair, P.K.R., Nair, V.D., 2008. Carbon stock and sequestration potential of traditional and improved agroforestry systems in the West African Sahel. Agr. Ecosyst. Environ. 125, 159-166.

Torello-Raventos, M., Feldpausch, T.R., Veenendaal, E., Schrodt, F., Saiz, G., et al., 2013. On the delineation of tropical vegetation types with an emphasis on forest/savanna transitions. Plant Ecol. Divers. 6, 101-137.

Tucker, C.J., 1979. Red and photographic infrared linear combinations for monitoring vegetation. Remote Sens. Environ. 8, 127-150.

Valbuena, R., Heiskanen, J., Aynekulu, E., Pitkänen, S., Packalen, P., 2016. Sensitivity of aboveground biomass estimates to height-diameter modelling in mixed-species West African woodlands. PLoS ONE 11, e0158198.

Vogelmann, J., Rock, B.N., Moss., D.M., 1993. Red edge spectral measurements from sugar maple leaves. Int. J. Remote Sens 14, 1563-1575.

Vågen, T.-G., Winowiecki, L.A., 2013. Mapping of soil organic carbon stocks for spatially explicit assessments of climate change mitigation potential. Environ. Res. Lett. 8, 015011.

Vågen, T.-G., Winowiecki, L.A., Abegaz, A., Hadgu, K.M., 2013a. Landsat-based approaches for mapping of land degradation prevalence and soil functional properties in Ethiopia. Remote Sens. Environ. 134, 266-275.

Vågen, T.-G, Winowiecki, L., Tamene Desta, L., Tondoh, J., 2013b. The land degradation surveillance framework (LDSF)—field guide v3-2013. World Agroforestry Centre, Nairobi. Vågen, T.-G., Winowiecki, L.A., Tondoh, J.A., Desta, L.T., Gumbricht, T., 2016. Mapping of soil properties and land degradation risk in Africa using MODIS reflectance. Geoderma 263, 216-225.

Waddell, K.L., 2002. Sampling coarse woody debris for multiple attributes in extensive resource inventories. Ecol. Ind. 1, 139-153.

White, F., 1983. The vegetation of Africa. A descriptive memoir to accompany the Unesco/AETFAT/UNSO vegetation map of Africa. UNESCO, Paris.

World Agroforestry Centre, 2015. Tree functional attributes and ecological database. http://db.worldagroforestry.org (accessed 19.10.2015) 
Wu, W., De Pauw, E., Helldén, U., 2013. Assessing woody biomass in African tropical savannahs by multiscale remote sensing. Int. J. Remote Sens. 34, 4525-4549.

Wulder, M.A., Hilker, T., White, J.C., Coops, N.C., Masek, J.G., et al., 2015. Virtual constellations for global terrestrial monitoring. Remote Sens. Environ. 170, 62-76.

Zanne, A.E., Lopez-Gonzalez, G., Coomes, D.A., Ilic, J., Jansen, S., et al., 2009. Global Wood Density Database. http://datadryad.org/handle/10255/dryad.235 (accessed 19.10.2015)

Zhu, Z., Woodcock, C.E., 2012. Object-Based cloud and cloud shadow detection in Landsat imagery. Remote Sens. Environ. 118, 83-94.

Zvoleff, A., 2015. glcm: Calculate Textures from Grey-Level Co-Occurrence Matrices (GLCMs). R package version 1.4. http://CRAN.R-project.org/package=glcm 